\title{
Las madres de los expósitos en España en la segunda mitad del siglo XIX
}

\author{
The foundling's mothers in Spain \\ in the second half of the 19 th century
}

Ana María Rodríguez Martín

Recibido: 3/04/2019

Aceptado: 5/01/2020

\section{RESUMEN}

Los objetivos de este artículo son el análisis de las diferencias entre la realidad y la visión social y literaria de las madres que abandonaban a sus hijos y luego los recuperaban, y el estudio de las causas que las empujaban a efectuar ambas acciones, todo ello en la segunda mitad del siglo XIX. Las fuentes que hemos utilizado son los libros de matrícula y los expedientes de los ingresados en la Casa de Maternidad y Expósitos de Barcelona, que nos han permitido analizar las naturalizaciones y las legitimaciones y, además, establecer las características de las madres que las realizaban. Estos resultados los hemos confrontado con la visión que la literatura, la prensa y bibliografía de la época daban de los abandonos de niños y de las mujeres que los efectuaban. La conclusión principal es que era la pobreza, sobre todo, la causa de los abandonos de los hijos, y que esta acción comportaba el rechazo social hacia sus madres.

Palabras clave: inclusas, expósitos, madres, naturalizaciones, España, siglo XIX.

\section{ABSTRACT}

This article analyses the differences between real life and the social and literary vision of mothers who abandon their children, of those who will recovered them later and the causes that pushed them in both directions during the second half of the 19th century. Our sources are the registration book and the records of the inmates in the Casa de Maternidad y Expósitos de Barcelona (Maternity and foundling Home of Barcelona) these above mentioned sources have allowed us to analyze the processes of naturalization and legitimization of children living in the Casa de Maternidad y Expósitos de Barcelona and also to established the features of the mothers who turned to these processes. These results have been compared with the vision that different literary works, press articles and books of the time gave of children abandonment, mothers' responsibilities and profiles. The main conclusion is that poverty more than dishonour was the reason that pushed some mothers to abandon their children, and this abandonment carried out social rejection.

Keywords: orphanages, foundlings, mothers, naturalizations, Spain, second half of the 19th century.

Ana María Rodríguez Martín es Doctora en Historia por la Universidad de Barcelona y Catedrática de Educación Secundaria en Barcelona. Correo electrónico: anarmartin@yahoo.es. ID: https: / / orcid.org/0000-0003-1799-0939

Cómo citar este artículo: Rodríguez Martín, A.M. (2019). Las madres de los expósitos en España en la segunda mitad del siglo XIX. Atlánticas. Revista Internacional de Estudios Feministas, 4 (1), 240-264. doi: http: / / dx.doi.org/10.17979/ arief.2019.4.1.5232 


\section{INTRODUCCIÓN}

La mayoría de los estudios sobre las inclusas se centran en los expósitos', es decir, en los niños abandonados o expuestos, o bien confiados a un establecimiento de beneficencia2. Sin embargo, este artículo lo hemos enfocado sobre sus madres y, más concretamente, sobre las que luego recuperaban a sus hijos depositados en la Casa de Maternidad y Expósitos de Barcelona (a partir de ahora, CMEB). Hemos centrado este estudio en la segunda mitad del siglo XIX porque este período nos permite ver el funcionamiento de la institución antes citada fundada en 1853, y porque en 20-6-1849 se publicó la Ley de Beneficencia a la que, en 14-5-1852, siguió su Reglamento que organizó todo el sector y estuvo vigente hasta bien entrado el siglo XX.

Nuestras hipótesis son varias. La primera es que la sociedad condenaba a las mujeres que no cumplieran con el rol de cuidadoras de sus hijos. La segunda, es que esa condena ocultaba la pobreza y la falta de ayudas a las progenitoras, que se veían empujadas a abandonar temporalmente a sus hijos en una estrategia de supervivencia. La última hipótesis es que no se correspondía la visión que daba la literatura de la época con la realidad de las causas del abandono de niños.

Los objetivos de este artículo son varios. El primero es el estudio de las características de las madres que depositaban a sus hijos en la Casa de Maternidad y Expósitos de Barcelona y, posteriormente, los recuperaban. El segundo es el análisis de las causas que empujaban a estas mujeres a abandonar a sus hijos y, el último, el estudio de la consideración social de estas madres y la visión que la literatura daba de ellas. Para conseguir estos objetivos hemos consultado los libros de matrícula y los expedientes personales y de recuperación de estos niños, que nos han permitido conocer el número y las características de sus progenitoras, las causas por las que dejaron y luego recogieron a sus hijos, y la postura de la Institución respecto a estas mujeres.

\footnotetext{
1 En la Casa de Maternidad y Expósitos de Barcelona, al igual que en la inmensa mayoría de estos establecimientos benéficos, los porcentajes de ingresados y de fallecidos de uno y otro sexo estaban muy igualados, lo mismo que los de los recuperados y naturalizados por sus madres. Por esta razón, utilizamos el masculino genérico cuando nos referimos a las expósitas y expósitos. En este artículo lo importante y decisivo es el sexo de las personas que abandonaban y luego recuperaban a sus vástagos, y que sufrían el menosprecio social por haber concebido fuera del matrimonio.

2 Diccionario de la lengua española, Madrid, Espasa Calpe, 2004, p. 1.023.
} 
Esta realidad hemos querido compararla con la de otras inclusas y con la visión que la sociedad y algunas obras literarias daban sobre las madres que abandonaban a sus hijos y las razones que las movían a ello. Además, hemos pretendido ver si la literatura reforzaba o distorsionaba la realidad de los abandonos infantiles. Para todo ello hemos consultado bibliografía actual y de la época, diversas obras literarias y la prensa del período que analizamos.

\section{LAS MADRES QUE RECUPERABAN A SUS HIJOS EN LA CASA DE MATERNIDAD Y EXPÓSITOS DE BARCELONA, 1853-1894}

El Código Civil de 1889 consideraba como hijo natural al niño nacido, fuera de matrimonio, de padres que en el tiempo de su concepción hubieran podido casarse (Cámara, 1975). La naturalización de un expósito, contemplada en el Código Civil y en los reglamentos de las inclusas, consistía en cambiar su naturaleza de hijo de padres desconocidos y en otorgarle el apellido del progenitor o los de los progenitores que lo solicitasen. Muchas inclusas sólo concedían la naturalización si las personas interesadas pagaban los gastos ocasionados por el menor, aunque si presentaban una declaración de pobreza quedaban eximidos de este reembolso (Hospicio Provincial de Zaragoza, 1883).

En la CMEB, la persona que quisiera naturalizar a un expósito tenía que presentar dos certificados, uno de buena conducta expedido por su párroco, y otro de su alcaldía conforme poseía medios suficientes para mantener a su hijo. Además, debía aportar la partida del bautismo rectificada en la que constase el nombre y apellidos del progenitor que hacía la naturalización (Francisco, 1903). Para cambiar la inscripción en el Registro Civil el trámite más rápido y barato para la persona interesada y, por tanto, el más utilizado en ésta y otras inclusas españolas, era hacer testamento ante notario y reconocer en él a su hijo (Abella, 1903). En la CMEB las naturalizaciones fueron aumentando a lo largo del período que consideramos, como podemos ver en la tabla 1, en la que, debido a la altísima mortalidad, sobre todo de los menores de un año, hacemos constar también el porcentaje de naturalizaciones sobre los supervivientes. 
Tabla 1. Expósitos de la CMEB naturalizados, por generaciones, 1864-1894³

\begin{tabular}{|c|c|c|c|c|c|}
\hline \multicolumn{5}{|c|}{ número de niños } & \multicolumn{2}{c|}{$\%$ de naturalizados sobre } \\
\hline año & ingresados & supervivientes & naturalizados & ingresados & supervivientes \\
\hline 1864 & 729 & 198 & 3 & 0,41 & 1,51 \\
\hline 1869 & 704 & 186 & 5 & 0,71 & 2,68 \\
\hline 1874 & 653 & 114 & 9 & 1,38 & 7,89 \\
\hline 1879 & 677 & 190 & 17 & 2,51 & 8,95 \\
\hline 1884 & 649 & 253 & 23 & 3,54 & 9,09 \\
\hline 1889 & 570 & 294 & 40 & 7,02 & 13,7 \\
\hline 1894 & 671 & 311 & 35 & 5,22 & 11,25 \\
\hline
\end{tabular}

Fuente: Elaboración propia a partir de los datos contenidos en los legajos j-2.357, j-2.851 al j2.877, y en los libros de matrícula de 1853 a 1894, j-3.062 al j-3.102, del Archivo Histórico de la Diputación de Barcelona.

Creemos que el aumento de naturalizaciones en la CMEB se debió a que algunas progenitoras comenzaron a considerar la inclusa como una institución que, además de permitir ocultar la deshonra de un nacimiento ilegítimo, se ocupaba de sus hijos lactantes cuando ellas no podían alimentarlos y cuidarlos. Por ello, en el primer año de vida del menor no solía producirse la naturalización, porque comportaría su entrega a la madre y ésta tendría que lactarlo o pagar a una nodriza. Se trataba, entonces, de abandonos temporales, una estrategia de supervivencia que se practicaba también en otras inclusas (Valverde, 1994) porque aunque la mayoría de las mujeres pobres trabajaba, su salario era bajísimo y las jornadas laborales muy largas, tanto en el campo, como en las fábricas (Castro, 2007; Palomares, 1988). Además, no fue hasta el 13-3-1900 que se publicó la ley, incumplida de forma generalizada, que establecía para las mujeres una jornada diaria de once horas (Balcells, 1974), creaba el permiso de maternidad, no pagado, de tres semanas después del parto y concedía media hora por la mañana y otra por la tarde, que no se descontarían del salario, a las mujeres con hijos lactantes (Calle, 1989). Por lo tanto, antes de la ley que acabamos de citar las madres se encontraban sin ayuda alguna, situación agravada en profesiones que ya de por sí hacían muy difícil amamantar y cuidar de un hijo, como la de sirvienta, que comportaba un horario laboral ilimitado al ser internas muchas de las criadas (Ortiz, 2003).

3 En las generaciones de 1849, 1854 y 1859 no se produjo naturalización alguna. 
La casi totalidad de las naturalizaciones en la CMEB fue realizada por madres, de entre 20 y 30 años, solteras y que no habían nacido en Barcelona capital pero que residían en ella ${ }^{4}$. Este hecho se explica porque, en la segunda mitad del siglo XIX, la Ciudad fue concentrando progresivamente un mayor porcentaje de habitantes de la Provincia y, además, porque ejercía un gran poder de atracción sobre la población activa catalana, aragonesa y valenciana (Tatjer, 2002). Esa gran concentración urbana tenía como consecuencias que fuera en Barcelona donde se produjeran más nacimientos ilegítimos y también que fueran vecinas de esta Ciudad las mujeres que naturalizaban expósitos. La mayor industrialización de Barcelona determinó que, de estas madres, fueran más numerosas las dedicadas al sector secundario que al servicio doméstico. De algunas mujeres no hay datos sobre el trabajo que realizaban pero no por eso podemos concluir que no lo hacían, dado el gran volumen del trabajo femenino a domicilio, a tiempo parcial o estacional, que no era contabilizado. Incluso, en ciudades textiles de Cataluña, una cantidad importante de trabajadoras constaba como dedicada a sus labores en los censos nacionales de población (Borderías y Pérez-Fuentes, 2009).

Todas las personas que naturalizaban expósitos de la CMEB eran pobres, como constaba en el certificado municipal que tenían que presentar, en el que a veces se especificaba el jornal que cobraban, que era ínfimo. Además, a partir de 1883, en las escrituras notariales de naturalización se hizo constar alguna de las once categorías de cédula personal que se correspondían con la posición económica del que la detentaba. Pues bien, la de la última categoría era la de la inmensa mayoría de las madres que recuperaba a sus hijos 5 . Su pobreza se reflejaba en como los habían dejado en el torno, con poquísimas prendas viejas e, incluso, solo con un trozo de tela o desnudos (Rodríguez, 2005). Su situación económica también la podemos ver en como vivían estas mujeres, pues muchas estaban realquiladas. Además, su nivel cultural era bajísimo, dado que la mayoría ni sabía firmar . Las características de estas madres son similares a las del resto de las inclusas españolas: solteras y analfabetas, que trabajaban de sirvientas,

\footnotetext{
4 Archivo Histórico de la Diputación de Barcelona (a partir de ahora, AHDB), Fondo Diputación de Barcelona, expedientes de expósitos, legajos (a partir de ahora, leg.) j-2.851 al j-2.877, y j-2.357.

5 AHDB, Fondo Diputación de Barcelona, expedientes de expósitos, leg. j-2.851 al j-2.877.

6 Ibidem.
} 
costureras o jornaleras y, sobre todo, que eran pobres (Valverde, 1994; Rodríguez, 2008).

En las solicitudes de naturalización en la $\mathrm{CMEB}$, muchas redactadas por escribanos, era frecuente que constasen los motivos del abandono. El mayoritario era la pobreza', a la que podía unirse la falta de leche o la enfermedad de la madre, "La exponente enferma no tuvo otro recurso que implorar en esa dicha casa su amparo", "[...] para su lactancia fue depositada en ese benéfico Asilo"s. Estos motivos seguramente eran ciertos, dadas las malas condiciones en las que vivían y trabajaban las mujeres pobres (Prats, 1996). Sus viviendas eran insalubres, su alimentación mala y escasa, y las fábricas en las que trabajaban tenían unas pésimas condiciones higiénicas (Raduá, 1904; Serrano, 1980). Concepción Arenal resumía estas circunstancias perfectamente, "[...] la situación normal de la mujer que no tiene más recursos que su trabajo es la miseria" (Arenal, 1891). Incluso, las estadísticas reflejaban un mayor número de mujeres oficialmente pobres: en 1862 había 178.934 pobres de solemnidad mujeres frente a 83.657 hombres (Junta General de Estadística, 1866).

Las circunstancias negativas en las que vivían muchas mujeres podían provocar que algunas de ellas no pudieran amamantar. Para una madre pobre la falta de leche era un problema importante porque difícilmente podía pagar a una nodriza. Por esa razón las inclusas se presentaban como una solución, porque hasta principios del siglo XX, y nada más que en las ciudades más importantes, no se crearon las Gotas de Leche, que facilitaban este alimento de vaca cuando la madre no podía lactar a su hijo (Uribe, 1996).

Otros de los motivos del abandono que se citaban en las instancias de naturalización eran la falta de apoyo y el rechazo o la presión de la familia`. También se explicaba en ellas que las progenitoras habían sido separadas de su hijo contra su voluntad o por un error"1, o bien por el engaño, "Habiendo mi pretendiente tenido la imprudencia de meter a mi hija en la CMEB, pues me dijo que la habia confiado a una nodriza [...] y todos los meses me iba pidiendo el dinero para llevar a la nodriza hasta que descubri que en lugar de entregar la niña a una nodriza la habia

7 AHDB, Fondo Diputación de Barcelona, expedientes de expósitos, leg. j-2.865, j-2.867 y j-2.876.

8 Instancias a la CMEB, 1879 y 1893 . AHDB, Fondo Diputación de Barcelona, expedientes de expósitos, leg. j-2.864 y j-

2.876 .

9 AHDB, Fondo Diputación de Barcelona, expedientes de expósitos, leg. j-2.855 y j-2.856.

10 AHDB, Fondo Diputación de Barcelona, expedientes de expósitos, leg. j-2.860, j-2.862 y j-2.867. 
llevado a una inclusa"11. Algunas progenitoras alegaban el miedo a la deshonra, que iba ligado, normalmente, a la falta de responsabilidad o a la ausencia del padre de su hijo', "Al mes de nacida la niña, frustradas las esperanzas para casarse con el causante de su deshonra, falta de recursos y enferma, con todo el hondo pesar tuvo que consentir en que su pobre vástago fuera depositado en ese bendito establecimiento"iз $^{\prime \prime}$. Estas explicaciones reflejan que muchos embarazos no habían sido deseados, y que frente a ellos no era posible el aborto, pues durante todo el período que analizamos estuvo penado (Nash, 1994b). Para acoger a gestantes solteras o viudas que querían parir secretamente y, en la mayoría de los casos, dejar directamente a su hijo en la inclusa anexa, se crearon en muchas capitales de provincia maternidades públicas. Sin embargo, estas instituciones ofrecían pocas plazas, no reunían buenas condiciones de higiene y no solían contar con las salas de aislamiento adecuadas, lo que unido al poco desarrollo de la obstetricia tenía por consecuencia una alta mortalidad maternal (Hauser, 1902). En Barcelona, la maternidad provincial y pública no se creó hasta 1892. Antes de ese año, las mujeres solteras que desearan ocultar el embarazo y el parto ingresaban en la Sala de Retiradas del Hospital de la Santa Cruz, que disponía de muy pocas camas (Rodríguez, 2005).

En la CMEB las naturalizaciones se producían, según las instancias de las madres, cuando habían desaparecido las causas que las habían empujado al abandono de su hijo, o bien cuando habían obtenido el perdón familiar o no soportaban los remordimientos ${ }^{14}$, "La exponente en todo este tiempo transcurrido no ha dejado de verse acosada de los más acervos remordimientos, considerando el abandono de su hijo a que había incurrido, dejándole sin nombre de padres y sin noticias de quien le había dado el ser" ${ }_{15}$. Una vez realizados todos los trámites de la naturalización, el paso siguiente era la entrega del niño por parte de la CMEB, aunque el Reglamento del 14-5-1852 para la ejecución de la Ley de Beneficencia del 20-6-1849 restringía la entrega de los expósitos a las madres que observasen buena conducta, según el criterio de las juntas de gobierno de las inclusas y las diputaciones provinciales de las que dependían (Maza, 1987). En los años que analizamos, en los expedientes de naturalización de la CMEB constan los

11 Instancia a la CMEB, 22-8-1880. AHDB, Fondo Diputación de Barcelona, expedientes de expósitos, leg. j-2.865. 12 AHDB, Fondo Diputación de Barcelona, expedientes de expósitos, leg. j-2.864.

13 Instancia a la CMEB, 25-4-1893. AHDB, Fondo Diputación de Barcelona, expedientes de expósitos, leg. j-2.876.

14 AHDB, Fondo Diputación de Barcelona, expedientes de expósitos, leg. j-2.296, j-2.857, j-2.864, j-2.867, j-2.868 y j-2.876.

15 Instancia a la CMEB, 1874. AHDB, Fondo Diputación de Barcelona, expedientes de expósitos, leg. j-2.862. 
informes parroquiales y municipales de conducta de las solicitantes, y todos son positivos, por lo que los niños reclamados fueron entregados. Sin embargo, ya en la última década del siglo XIX, encontramos algún informe negativo y, además, la CMEB hacía indagaciones reservadas para comprobar la moralidad de las madres que querían recuperar a sus hijos. La consecuencia era que, en alguna ocasiones, la Institución no accedía a devolver el niño a su progenitora basándose en cuestiones morales (Rodríguez, 2003).

También eran recogidos por su progenitora o progenitores algunos niños que al nacer habían sido bautizados y reconocidos, pero tras un cierto tiempo, que variaba entre unos días y unos meses, habían sido depositados en la CMEB. El porcentaje de recuperaciones fue muy alto, como podemos observar en la tabla 2 , en la que no vemos la categoría de hijo natural en los ingresados antes de 1879 porque no se hacía constar en los libros de ingreso.

Tabla 2. Hijos naturales recuperados por sus padres en la CMEB, por generaciones, 1879-1894

\begin{tabular}{|c|c|c|c|c|}
\hline \multicolumn{3}{|c|}{ hijos naturales } & \multicolumn{2}{c|}{ recogidos sobre los supervivientes } \\
\hline año & ingresados & supervivientes & número & porcentaje \\
\hline 1879 & 3 & 2 & 0 & 0 \\
\hline 1884 & 20 & 10 & 7 & 70 \\
\hline 1889 & 1 & 1 & 1 & 100 \\
\hline 1894 & 13 & 11 & 7 & 63,64 \\
\hline
\end{tabular}

Fuente: Elaboración propia a partir de los datos contenidos en los libros de matrícula de 1853 a 1894, j-3.062 al j-3.102, del Archivo Histórico de la Diputación de Barcelona.

En estas solicitudes de recuperación, realizadas mayoritariamente por las madres, se explicaban los motivos que les habían empujado a dejar a sus hijos en la CMEB, que eran, generalmente, la propia enfermedad y la miseria, aunque en alguna instancia se declaraba que el abandono se había producido en contra de la voluntad de la solicitante ${ }^{16}$, "Fue bautizada y entregada (la niña) en ese establecimiento por la comadrona asistente en contra de la voluntad de la infrascrita, debido a que después del parto arrostró una larga enfermedad"1".

16 AHDB, leg. j-3.097.

17 Instancia a la CMEB, 1889. AHDB, leg. j-2.872. 
Un número reducido de niños de la CMEB fue recogido tras haber sido legitimado por sus padres, es decir, tras haberse casado éstos, declarar ser progenitores del menor, y efectuar los cambios pertinentes en el libro de bautismo y, a partir de 1870, también en el Registro Civil, según establecía el Código Civil de 1889 en sus artículos 119-121. Estos padres en sus instancias detallaban los motivos que les habían llevado a abandonar a sus hijos. Uno era el deseo de evitar la vergüenza de la madre y el escándalo ${ }^{18}$, y el otro, la pobreza, visible en sus cédulas personales, que eran de las dos últimas categorías $^{19}$. La imposibilidad de pagar a un ama de leche explica que algunos de estos niños fueran legitimados cuando estaban ya destetados, "[...] la madre no pudo continuar amamantado al niño por enferma y a la falta de recursos de ambos por ser pobres y no poderle costear una nodriza" ${ }^{\prime 20}$. Frente a la incapacidad de las madres para amamantar, solo algunas inclusas les concedían ayudas a la lactancia para que pudieran pagar a una nodriza durante un año o año y medio (Uribe, 1996).

Una serie de criaturas, nacidas de legítimo matrimonio, fueron depositadas en el torno de la CMEB. En muchas ocasiones llevaban notas que citaban las razones del abandono. Entre ellas estaban la pobreza, el fallecimiento del progenitor y la incapacidad de la viuda para sacar adelante a todos los hijos, la falta de leche de la madre, y la ausencia del padre en el hogar familiar. En muchos casos, pasado un cierto tiempo, uno o los dos cónyuges, o algún pariente, recogían a estos menores que, al haber sido abandonados en el torno sin documento oficial alguno, habían sido anotados en los libros de registro de la Institución como hijos de padres desconocidos (Rodríguez, 2009).

Si consideramos a todos los niños recuperados, ya fueran naturalizados o legitimados, o bien a los que estaban ya reconocidos como hijos naturales pero fueron luego abandonados, veremos que son un porcentaje cada vez más alto de los ingresados $\mathrm{y}$, sobre todo, de los supervivientes, como podemos ver en la tabla 3. Estos niños fueron recogidos por uno o los dos progenitores y, en muy pocos casos, por algún pariente.

18 AHDB, Fondo Diputación de Barcelona, expedientes de expósitos, leg. j-2.851, j-2.854, j-2.856, j-2.862 y j-2.867. 19 AHDB, Fondo Diputación de Barcelona, expedientes de expósitos, leg. j-2.851 al j-2.877, y leg. 772.

20 Instancia a la CMEB, 1890. AHDB, Fondo Diputación de Barcelona, expedientes de expósitos, leg. j-2.873. 
Tabla 3. Asilados de la CMEB recuperados por sus madres, padres o familiares, por generaciones, 1864-1894

\begin{tabular}{|c|c|c|c|c|c|}
\hline \multicolumn{4}{|c|}{ número de niños } & \% de recuperados sobre los \\
\hline año & ingresados & supervivientes & recuperados & ingresados & supervivientes \\
\hline 1864 & 729 & 198 & 6 & 0,82 & 3,03 \\
\hline 1874 & 653 & 114 & 10 & 1,53 & 8,77 \\
\hline 1884 & 649 & 253 & 53 & 8,17 & 20,95 \\
\hline 1894 & 671 & 311 & 62 & 9,24 & 19,93 \\
\hline
\end{tabular}

Fuente: Elaboración propia a partir de los datos contenidos en los legajos j-2.357, j-2.851 al j2.885, y en los libros de matrícula de 1853 a 1894, j-3.062 al j-3.102, del Archivo Histórico de la Diputación de Barcelona.

Estos porcentajes confirman el uso que a las inclusas daban, cada vez más, las madres y padres que allí dejaban a sus hijos: un depósito temporal que les permitiera seguir trabajando o superar una situación adversa.

\section{LA CONSIDERACIÓN SOCIAL DE LAS MADRES DE LOS EXPÓSITOS EN ESPAÑA EN LA SEGUNDA MITAD DEL SIGLO XIX}

En España, las mujeres embarazadas solteras, viudas o adúlteras no gozaban de consideración social alguna y eran vistas como unas transgresoras porque hacían añicos la idea dominante, sostenida por algunos médicos, la Iglesia y la moral social, de que la mujer honrada debía ser pasiva y carente de deseo (Lozano, 2006). Concepción Arenal resumía así la situación de las mujeres que tenían hijos fuera del matrimonio,

"Se sabe y se encarece, que por la maternidad [...], es acreedora la mujer á cuantos respetos $y$ distinciones se le tributen; $y$ no obstante, la maternidad, carga insoportable para muchas desgraciadas, es para muchísimas un sangriento calvario, en el cual la degradación, la vergüenza, la deshonra, la indigencia, y aún el crimen, forman el único cortejo de las víctimas" (Arenal, 1877: 149). 
El período que consideramos en este artículo está marcado, en 1854, por la proclamación del dogma de la Inmaculada Concepción, la intensificación de la imagen de la Virgen María como modelo femenino y por el afianzamiento, a lo largo de la segunda mitad del siglo XIX, de la idealización y exaltación de la maternidad. En ese contexto, las mujeres embarazadas fuera del matrimonio eran vistas como una anomalía (Roigé, 1977; Lozano, 2006). Por su parte, la prensa femenina presentaba la virginidad como una joya a perder solamente en el matrimonio, y si no era así, el destino de la mujer sería, a largo plazo, la soltería, la soledad y los remordimientos (Perinat y Marrades, 1980). También se denostaban los nacimientos ilegítimos, cuyo número era el barómetro de la moral de una nación, según algunos tratadistas. Por su lado, los higienistas consideraban, a finales del siglo XIX, que la ilegitimidad y la miseria aumentaban las probabilidades de que una mujer abandonase a su hijo porque las solteras embarazadas, en muchos casos, sufrían el rechazo en su hogar familiar y luego, cuando parían, no podían trabajar, y si lo hacían solo contaban con su escaso salario para subsistir. Además, los hijos ilegítimos tenían una mortalidad muy alta, superior incluso a la de los legítimos de padres pobres (Cohen, 1996; Ríos, 2006).

La familia era considerada la base de la sociedad, la que aseguraba el orden moral y material. Dentro de ella, la mujer debía ser el ángel del hogar (Nash, 1994a), la madre amorosa y abnegada, que cumplía con los deberes que la naturaleza le había impuesto, que era el de engendrar, alimentar, cuidar, educar y conservar con vida a sus hijos (Lozano, 2000; Palacio, 2007; Ríos, 2010). Por esa razón, las madres que no cumplían la que se creía que era su función en la vida y dejaban a sus hijos en el torno de una inclusa, en un descampado o en cualquier lugar público, eran muy criticadas por la prensa, "Hay madres sin entrañas que abandonan a su hijos en la calle o en el torno salvador de la Inclusa" (Guerola, 1882: 167). Además, estas mujeres destrozaban la creencia generalizada en el instinto maternal y rompían el ideal burgués, acentuado a finales del siglo XIX, de la madre totalmente entregada a sus hijos y su familia (Casas, 1889),

"[...] las madres que, debido a alguna ligereza, llegaron a tener un hijo, al cual arrojaron a la Inclusa negándole sus caricias y su amor, o que en lugar de 
depositarlo en el establecimiento de referencia cometieron con él cualquier acto vandálico, merecen ser: por un lado despreciadas de todos y tratadas como si fueran unas mujeres antropófogas, y, por otro, compadecidas, supuesto que toda madre que así procede, carece en absoluto de razón y dominio sobre sí misma en aquel acto" (Alén, 1901: np).

El rechazo social no alcanzaba a los padres. La responsable era siempre la madre, censurada por dejar a su hijo en la inclusa. En general, las críticas dejaban de lado la pobreza femenina y no proponían ayudas, que ya existían a finales del siglo XIX en varios países europeos (Fuchs, 2003), que permitieran a las madres conservar a su hijo a su lado. Las críticas tampoco citaban el porcentaje tan alto de recuperaciones sobre los expósitos supervivientes y solo insistían en el egoísmo de las progenitoras. Concepción Arenal, por su parte, consideraba que aunque algunas mujeres que echaban a sus hijos al torno creían que los dejaban al buen cuidado de instituciones públicas, la altísima mortalidad de las inclusas rompía esta suposición, "El torno donde se deja morir de hambre a los niños, es una criminal hipocresía; no sirve más que para quitar a las madres el remordimiento de inmolar a sus hijos, y a la sociedad el horror de dejar perecer, por falta de auxilio, a los desventurados inocentes" (Arenal, 1901: 511). Efectivamente, en las inclusas el número de fallecimientos era muy elevado porque los edificios que ocupaban no estaban en buenas condiciones, no se respetaban las normas mínimas de aislamiento de los enfermos y, sobre todo, las diputaciones provinciales no destinaban los fondos necesarios para tener el número suficiente de nodrizas, tanto internas como externas, que garantizasen una buena lactancia a cada expósito y así favorecieran su supervivencia (Valverde, 1994; Aguilar et al., 2004).

Frente a las críticas a las madres de los expósitos, dos médicos de instituciones de beneficencia nos ofrecen una visión muy diferente. El primero, Aguirre Barrio, culpaba totalmente de los abandonos a la misma sociedad, pues permitía la situación desesperada de las madres solteras: "Rodeadas de contrariedades y dominadas por la miseria, sin encontrar en ninguna parte socorro para sus pequeños ni para el sustento propio, llega un momento en que [...] después de haber agotado fuerzas y paciencia, los depositan en el torno de la Inclusa" (Aguirre, 1885: 
117-8). El segundo facultativo, Coll y Bofill, abominaba del secretismo de las maternidades, disculpaba la flaqueza de las mujeres que acudían a ellas, y señalaba el rechazo social del que eran objeto las progenitoras que dejaban a sus hijos en las inclusas: "De cuanto contribuye a ese desdichado acto (el abandono), corresponde a la sociedad una buena parte por ser aquel como la resultante de la situación anormal en que las madres se ven colocadas ante ella y que las impulsa a seguir ese camino" (Coll, 1900: 75-6).

\section{LOS ABANDONOS MATERNALES EN ALGUNAS OBRAS LITERARIAS ESPAÑOLAS EN LA SEGUNDA MITAD DEL SIGLO XIX}

Habiendo visto las características y la consideración social de las madres que abandonaban y luego recuperaban a sus hijos, vamos a fijarnos ahora en el retrato que de estas mujeres hacen diversas obras literarias de las que no pretendemos hacer un estudio crítico, sino analizar aspectos relacionados con el tema central de este artículo. Los criterios de selección de las obras han sido varios. El primero no radica en la relevancia de los autores, su ideología o su sexo, sino en que aparezca en la pieza la separación, forzada o voluntaria, de una madre y su hijo, y el intento de recuperación del menor por parte de la progenitora. El segundo criterio es que en las obras elegidas se expliquen las causas del abandono, se reflejen los valores de la sociedad en la que vivían sus autores o la consideración social de los expósitos y sus madres. La última circunstancia que hemos tenido en cuenta ha sido el período en el que fueron escritas o publicadas, la segunda mitad del siglo XIX, y hemos dejado de lado la pertenencia de estas obras a un determinado movimiento literario.

En las obras consultadas, la causa principal de los abandonos era el miedo al deshonor, que hemos visto que era también muy citado en las solicitudes de recuperación de expósitos de la CMEB por parte de sus madres. La protagonista de Los pecados capitales, en el parto de su hijo, fruto de una violación, exclamaba “iNingún testigo! ¡Que me mate el dolor, pero no la vergüenza! Dejadme morir aquí, pero ocultad, ocultad bien a mi hijo" (Navarro y Alba, 1883: 26). La conservación del honor era la causa de que a algunas protagonistas solteras les fueran arrebatados sus hijos por parte de sus allegados, que podían ser los abuelos 
(Pedroso, 1879) o los hermanos, como en Doña Berta. En este relato de Clarín está magníficamente descrito como el honor familiar residía en la castidad de las mujeres solteras y como los varones actuaban de forma drástica para borrar las pruebas de su pérdida. En este caso, condenando a su hermana a la soledad, "Se le robó el hijo, y los hermanos, los ladrones, la dejaron sola en Posadoiro [...] ya que había manchado la casa solariega pecando alli, se le dejaba el lugar de su deshonra, donde estaría más escondida que en parte alguna" (Alas, 1969: 27). También algunas madres de las que recogieron a sus hijos en la CMEB explicaban en sus solicitudes, como ya hemos visto, que habían sido separadas de su hijo en contra de su voluntad. No obstante, la mayoría de los expósitos eran dejados en el torno por decisión materna, y la causa principal que alegaban para haberlo hecho, una vez que se decidían a recuperarlos, era la pobreza, al contrario de lo que hemos visto en la mayoría de las obras consultadas, que era el deshonor. Las dificultades económicas en estas piezas literarias se citan poco o se hace referencia a ellas indirectamente, como en Misericordia, en donde la mujer que había abandonado a su hijo en la inclusa era una criada (Pérez Galdós, 1992). En otras obras, la pobreza se ve en las ropas, escasas y raídas, con las que es dejado un niño a la puerta de una casa (Caballero, 1862). Solamente en El expósito del Ródano el motivo era diferente a los anteriores. La madre estaba casada y era marquesa, pero había sido asesinada por su esposo en un rapto de locura, y por eso el niño había sido expuesto (Roselló, 1872).

En casi todas las obras que hemos visto no se pone en duda el amor maternal a pesar del abandono, y por eso se describen las separaciones de forma muy dramática, "-Llevar una hija en mis entrañas por espacio de nueve meses, darle la vida entre dolores crueles [...] y no volver a verla nunca! ¡Oh! ¡Esto es horroroso!" (García, 1861: 10). Nada más dos piezas de las analizadas presentan madres atípicas. En la primera, la mujer había llegado a olvidar al hijo dejado en la inclusa y se había casado con un hombre viejo (Roca, 1886). En la segunda, la progenitora, mientras su esposo estaba en el extranjero, había abandonado a su hijo para seguir a su amante. No obstante, la madre, que había actuado a instancias del seductor, había dejado al niño en la puerta de un hogar inmejorable, "[...] en una casa, en la que con devoción, paz y alegría de corazón se celebraba la Noche-buena, y donde pensó que hallaría amparo en la caridad de tan buenas almas" (Caballero, 
1862: 234). En la novela se castiga a la progenitora por su acción, pues fue abandonada por su amante, tuvo que dedicarse a la prostitución, y murió en un hospital llena de lacras. En esta misma obra constatamos el desprecio social hacia las madres que abandonaban a sus hijos, que ya hemos visto en el apartado anterior, a través de las opiniones de la viuda propietaria de la casa en cuya puerta había aparecido el menor, y de su criada, "Ni fue Madre, ni fue Mujer la que abandonó a un hijo suyo" (Caballero, 1862: 233), “ Habrase gran picarona la que así haya abandonado a su hijo! [...] ¡Tunantona! ¡Rufiana! ¡Hereje! ¿Si se habrá figurado esa judía que esta casa es la inclusa?" (Caballero, 1862: 234). Otras veces a este tipo de mujer se la considera una fiera o que no tiene corazón, "Ninguna madre se separa voluntariamente del hijo de sus entrañas, a menos de ser aquella una fiera" (Pedroso, 1879: 491), "A inclusa, facer non se fixo máis que pras mais que non teñen corazón (Rodríguez López, 1997: 189).

En muchas de las obras analizadas, las progenitoras se lamentan por haber perdido a sus hijos e intentan recuperarlos. En Los tres hijos del crimen, la tristeza persigue a la madre y por eso decide buscar a su niño, "[...] cuando se me oprime de pesar el corazón, me acuerdo de aquel hijo que dí a luz [...] no estaré tranquila hasta poner de mi parte todos los medios que están a mi alcance para averiguar su paradero" (García, 1861: 210). En Doña Berta, la protagonista en su vejez ya no acepta la separación de su hijo impuesta por sus hermanos y en su búsqueda recupera su identidad, que había perdido junto con él (Sotelo, 2005). En Los tres hijos del crimen, encontrar al hijo significaba la felicidad materna, ";Oh! Como yo le encontrase [...] como yo pudiese estrecharle entre mis brazos una sola vez, indudablemente sería feliz" (García, 1861: 284-5). Solamente en dos de las obras consultadas la madre no buscó a su niño. En las demás, el resultado de las gestiones maternas fue positivo, menos en Doña Berta, pues su hijo había fallecido (Alas, 1969). Sin embargo, en la realidad, no en la ficción, no siempre se producía la recuperación y en muchos casos era imposible dada la gran mortalidad que había en las inclusas y también en la CMEB.

El papel masculino en estas piezas literarias es pequeño, en consonancia con la realidad de los abandonos y las posteriores recuperaciones de los niños, efectuadas, en la mayoría de los casos, y como hemos visto, por mujeres. En tres 
de estas obras en las que el recién nacido es depositado en el torno, aparece la soledad de la madre en el parto porque el padre o bien había desaparecido en un naufragio o en la guerra antes de casarse (Roca, 1886; Alas, 1969), o bien era un seductor que se había desentendido de su amante y de su embarazo (García, 1861). Frente a los intentos de recuperación de sus hijos por parte de las madres, solo encontramos, en las obras consultadas, un hombre haciendo lo mismo ${ }^{21}$, pero por puro interés económico, porque así sería el administrador de la fortuna que iba a heredar el menor al morir la madre, gravemente enferma. Es entonces cuando busca a su hijo, no antes. En esta obra, Lo bordet, vemos el distinto rasero moral, según se tratase de hombres o mujeres, " $A$ un padre que tiene un hijo natural y lo mete en su casa, todo el mundo lo respeta, todo el mundo lo alaba: lo que para la mujer es una mancha, para el hombre es una honra"22 (Roca, 1886: 69).

Respecto a los niños abandonados, las obras literarias analizadas nos proporcionan dos visiones opuestas. La primera es la de que eran producto del vicio, como afirmaba el protagonista de O locura o santidad cuando se enteró de que era el hijo secreto de una criada soltera, "[...] cubrir un nacimiento ilegítimo con un nombre honrado, es envolver en manto de armiño la podredumbre del vicio" (Echegaray, 1877: 52). También eran pobres, como la expósita protagonista de La hija del mar, de Rosalía de Castro, que vivía sola en una choza (Castro, 1945). Además, cargaban con la culpa de sus padres, como explica en Los tres hijos del crimen una madre a su antiguo amante, respecto a la niña que tuvieron en común, expósita y adulterina, "[...] nuestra hija lleva en su frente la mancha del crimen de sus padres, y las culpas de los padres han de recaer sobre los hijos hasta la tercera y cuarta generación" (García, 1861: 279). Por eso, en dos obras de las examinadas, los expósitos al llegar a adultos seguían arrastrando el pecado de sus progenitores y les resultaba difícil contraer matrimonio. En Lo bordet, el padre de la joven a la que pretendía el inclusero protagonista lo expresaba claramente, "Yo mismo [...] soy capaz de recoger uno (expósito) [...] pero de eso, a consentir que su sangre se mezcle con la mía; de eso a consentir que mi única hija se

\footnotetext{
21 No contamos al padre de $A$ cruz de salgueiro, porque aunque es verdad que saca a su hija de la inclusa, no lo hace en calidad de progenitor y, además, la lleva a su casa como criada. Solo le dice que es su padre cuando ella decide casarse y él, conmocionado, advierte que el novio es otro hijo suyo del que no sabía su paradero.

22 Traducción de la autora del artículo. En catalán y conservando la ortografía original, el texto es el siguiente: “ $A$ un pare que tè un fill natural y se'l fica a casa, tothom 'l respeta, tothom l'alaba: lo que per la dona es una taca, per l'home es un'honra".
} 
una con un hombre, que no puede dar razón ni de su nacimiento ni de sus padres..." ${ }_{23}$ (Roca, 1886: 24). En Elia, la protagonista tenía vedado casarse, según opinaban sus conocidos, ya no con un caballero, ni siquiera con una persona decente. El motivo era la ausencia de padres y apellidos, "[...] la falta de nacimiento levanta una barrera entre dos seres que se aman" (Caballero, 1968: 111). Todos estos inconvenientes hacían que Rosalía de Castro presentase a los expósitos como seres marginados y tristes, "[...] todos esos desamparados seres que vagan sobre la tierra, como frías y solitarias sombras, como hojas que arrastran los vientos encontrados" (Castro, 1945: 103).

La segunda visión literaria presenta a los expósitos muy favorablemente (García, 1861; Roca, 1886), bondadosos y guapos los varones, y puras y hermosas las chicas, capaces todos ellos de contraer un matrimonio ventajoso y de ascender socialmente tras el descubrimiento de que sus padres eran personas

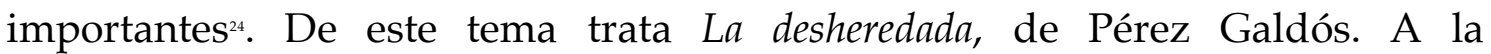
protagonista, cuando se queda huérfana, un tío suyo le cuenta que, en realidad, es hija de una persona principal, por lo que ella empieza a fabular un maravilloso porvenir cuando su verdadera madre, que se habría visto obligada a ocultarla y a entregarla para su crianza a una familia pobre, volviera a recogerla, "No es caso nuevo ni mucho menos -decía-. Los libros están llenos de casos semejantes ¡Yo he leído mi propia historia tantas veces...!" (Pérez Galdós, 1985: 5354). La muchacha, persiguiendo su sueño, acaba en la prostitución.

Dos estudios sobre diversas obras literarias francesas del siglo XIX establecen en ellas una serie de características que se repiten y que, en algunos casos, son comunes a las obras españolas que hemos analizado (Boudet, 1991; Jaspard, 1991), como el retrato positivo de las madres, que son presentadas como víctimas porque aunque aman a sus hijos tienen que abandonarlos por dos razones muy graves, el deshonor y la miseria. La primera, ligada a mujeres de

23 Traducción de la autora del artículo. En catalán y conservando la ortografía original, el texto es el siguiente: “Jo mateix...soch capás de recullirne un (expòsit)...pero de aixó á permetre que la sèva sanch se barreji ab la mèva; de aixó á consentir que la mèva única filla s'enllasi ab un home, que no pot donar rahó ni de son naixement ni dels sèus pares...".

24 En El Expósito del Ródano, al final se descubre que el protagonista era hijo de un marqués, y en Lo Bordet, que el joven inclusero era legítimo, por lo que recibe la herencia de su padre y contrae matrimonio con la hija de un notario. En Los tres hijos del crimen, resultó que los padres de la expósita eran una condesa y el Presidente del Consejo de Ministros. En A cruz de salgueiro, la inclusera Dolores, sirvienta de un ingeniero importante, fue reconocida como su hija y, posteriormente, se casó con un joven con carrera y un gran porvenir. 
la burguesía o la nobleza, y la segunda a las madres pobres y trabajadoras, que ven en el abandono la única oportunidad para que su querido hijo pueda sobrevivir. En otros casos, sobre todo si se trataba de mujeres adineradas o nobles, eran los familiares los que trasladaban a la embarazada soltera a un lugar lejano para que pariera en secreto, o bien llevaban al recién nacido a la casa de una nodriza para que discretamente lo alimentase y educase. Respecto a los expósitos, tanto en las obras españolas como en las francesas se ve el rechazo social hacia ellos. En las primeras, reflejado en sus dificultades a la hora de contraer matrimonio, y en las segundas, en el retrato que se hace de ellos, como jóvenes feos y maliciosos, dado que habían sido criados sin cariño.

\section{CONCLUSIONES}

Aunque muchas madres en las solicitudes a la CMEB de recuperación de sus hijos citaran la deshonra como causa del abandono, la pobreza era el motivo principal que las había empujado a ello. La mayoritaria última categoría de las cédulas personales de estas mujeres, los trabajos a los que se dedicaban, su analfabetismo y el hecho de que recuperasen a sus hijos cuando estaban ya destetados o, incluso, más tarde, delatan una pobreza que no les permitía pagar a una nodriza si no tenían leche, y les impedía dejar el trabajo para amamantar a su niño. Esta pobreza era la que provocaba que el porcentaje de niños dejados en la CMEB y recogidos posteriormente por sus progenitoras fuera cada vez mayor, en una clara estrategia de supervivencia cada vez más practicada.

La CMEB, solo entregaba los asilados a las madres solteras que, habiéndolos naturalizado, observasen buena conducta certificada por su párroco y alcalde. Hasta la última década del siglo XIX los niños reclamados fueron entregados a sus madres pero, posteriormente, la CMEB comprobaba reservadamente la moralidad de las reclamantes y, en caso negativo, no les entregaba sus hijos.

La consideración social de las progenitoras que dejaban a sus hijos en las inclusas era nula dado que chocaban con el ideal dominante de mujer y madre. De ellas se destacaba su falta de moralidad y de sentimientos, y no su pobreza, y se afirmaba que si abandonaban a su hijo no era por falta de ayudas sino por 
sus propias carencias personales. Solo algunos médicos de la beneficencia pública no se alinearon con esta postura que culpaba totalmente a la madre del abandono, que consideraba que se trataba de una cuestión estrictamente individual, y que era la causa del probable fallecimiento del hijo dada la altísima mortalidad de las inclusas. Así, a estas mujeres se les cargaba con toda la culpa y se eximía de ella a los padres, a la sociedad y a las diputaciones provinciales que eran las instituciones que tenían la misión de velar por la vida de los expósitos.

La mayoría de las obras literarias consultadas insisten en el deshonor de las madres como causa de los abandonos y no en su pobreza, a pesar de que la realidad contradecía a la ficción. La misma visión opuesta la podemos observar respecto a la recuperación de los hijos, porque en las piezas analizadas se produce en la mayoría de los casos, mientras que ya hemos visto que en la $\mathrm{CMEB}$, al igual que en otras inclusas, las recuperaciones no son numerosas.

El rechazo social hacia las mujeres que habían abandonado definitivamente a sus hijos repercutía en ellos mismos, y lo vemos en las obras literarias analizadas cuando, ya de adultos, se encontraban con dificultades para casarse por el temor que había a emparentar con expósitos al ser considerados producto del vicio. Pero entonces la literatura entra de nuevo en contradicción con la realidad y vuelve a ocultar la pobreza que rodeaba a los expósitos porque en las novelas y obras de teatro que hemos visto, en muchas ocasiones, se descubre que estos jóvenes eran hijos de personas importantes y les esperaba un brillante porvenir. Los padres de los niños abandonados, sin embargo, eran poco criticados socialmente, y en las obras consultadas su papel es mínimo, tanto en lo que se refiere al abandono como a la recuperación de sus hijos, que pasan a ser cuestiones que incumben solo a las madres. 


\section{FUENTES DOCUMENTALES}

Archivo Histórico de la Diputación de Barcelona.

Fondo Diputación de Barcelona.

Expedientes de expósitos, legajos 772, j-2.357, j-2.357, j-2.851 al j-2.877, y j3.022 .

Libros de matrícula, libros j-3.062 al j-3.112

\section{FUENTES LITERARIAS}

Alas (Clarín), L. [1892]. (1969). Doña Berta y otros cuentos. Navarra: Salvat y Alianza.

Caballero, F. (1862). Cosa cumplida...solo en la otra vida: diálogos entre la juventud y la edad madura. Madrid: Tipografía Mellado.

Caballero, F. [1857]: (1968). Elia. Madrid: Alianza.

Castro, R. de (1945). La hija del mar. Buenos Aires: Ediciones Universal.

Echegaray, J. de (1877). O locura o santidad. Madrid: Imprenta de J. M. Ducazcal.

García, A. (1861). Los tres hijos del crimen. Vol. I. Madrid: P. Gracia y Orga.

Navarro, E. y Alba, P. (1883). Los pecados capitales. Madrid: Tipografía de M.P. Montoya y Cia.

Pedroso, A. (1879). Los misterios de La Habana. Barcelona: J. Molinas.

Pérez Galdós, B. [1881]: (1985). La desheredada. Madrid: Alianza.

Pérez Galdós, B. [1897]: (1992). Misericordia. Madrid: Anaya.

Roca, J. (1886). Lo bordet. Barcelona: Librería Española de López.

Rodríguez López, X. [1899]. (2009). A cruz de salgueiro e outros relatos. Santiago de Compostela: Xunta de Galicia.

Roselló, V. (1872). El expósito del Ródano. Barcelona: Nueva Biblioteca Hispana Americana. 


\section{BIBLIOGRAFÍA DE LA ÉPOCA}

Aguirre, J. (1885). Mortalidad en la primera infancia, sus causas y medios de atenuarlas. Madrid: Tipografía Hispano-Americana.

Alén, Cesáreo (1901). Amor de madre. El Áncora, 1.083, np.

Arenal, C. (1877). Centro protector de la mujer. La Voz de la Caridad, 178, 145-152.

Arenal, C. (1891). El trabajo de las mujeres. Boletín de la Institución Libre de Enseñanza, 15. Reproducido en (1974): La emancipación de la mujer en España. Madrid: Júcar.

Arenal, C. (1901). Artículos sobre beneficencia y prisiones. Madrid: Librería V. Suárez.

Casas, F.J. (1889). Los expósitos. Álbum literario, 79, 4-5.

Coll, J. (1900). Mortalidad infantil en Barcelona, sus causas y profilaxis. Barcelona: Imprenta Sucesor de F. Sánchez.

Francisco, C. (1903). Bodas de oro de la Casa de Maternidad y Expósitos de Barcelona. Barcelona: Casa Provincial de Caridad.

Guerola, A. (1882). Malos padres y malos hijos. La Voz de la Caridad, 299, 163169.

Hauser, P. (1902). Madrid bajo el punto de vista médico-social. Vol. I. Madrid: Sucesores de Rivadeneyra.

Hospicio Provincial de Zaragoza (1883). Reglamento para el régimen interior del Hospicio Provincial de Zaragoza. Zaragoza: Imprenta del Hospicio.

Junta General de Estadística (1866). Anuario estadístico de España, 1862:1865. Madrid: Imprenta Nacional.

Raduá, E. O. (1904). Etiología de la mortalidad en la urbe barcelonesa y manera de disminuirla. Barcelona: Casa Provincial de Caridad.

\section{BIBLIOGRAFÍA}

Abella, F. (1903). Manual del Registro Civil. Madrid: Imprenta de El Consultor. 
Aguilar, Raül et al. (2004). La Casa de Maternitat i Expòsits. Les Corts. Barcelona: Ayuntamiento y Diputación de Barcelona.

Balcells, A. (1974). Trabajo industrial y organización obrera en la Cataluña contemporánea, 1900-1936. Barcelona: Laia.

Borderías, C. y Pérez-Fuentes, P. (2009). Mujeres, trabajos y economías familiares en España (siglos XIX y XX). En C. Borderías (ed.), La historia de las mujeres: perspectivas actuales (pp. 269-308). Barcelona: Icaria.

Boudet, C. (1991). L'abandon dans la littérature française du XX siècle. L'histoire des deux victimes. En Enfance abandonnée et société en Europe, XIV-XX siècle (pp. 249-258). Roma: École Française de Roma.

Calle, M. D. de la (1989). La Comisión de Reformas Sociales 1883-1963. Política social y conflicto de intereses en la España de la Restauración. Madrid: Ministerio de Trabajo y Seguridad Social.

Cámara, M. de la (1975). Reflexiones sobre la filiación ilegítima en el Derecho Español. Madrid: Tecnos.

Castro, X. (2007). Historia da vida cotiá en Galicia: séculos XIX e XX. Vigo: Nigratea.

Cohen, A. (1996). La infancia entre la vida y la muerte. En J. M. Borrás (dir.), Historia de la infancia en la España contemporánea, 1834-1936 (pp. 107-148). Madrid: Ministerio de Trabajo y Asuntos Sociales.

Fuchs, R. G. (2003). Beneficencia y bienestar. En D. I. Kertzer y M. Barbagli (comps.), Historia de la familia europea. Vol. II (243-296). Barcelona: Paidós.

Jaspard, M. y Gillet, M. (1991). Enfants abandonnés et romans-feuilletons. Fragments de lecture (France 1850-1914). En Enfance abandonnée et société en Europe, XIV-XX siècle (pp. 679-701). Roma: École Française de Roma.

Lozano, M. (2000). Las imágenes de la maternidad. Alcalá de Henares: Ayuntamiento de Alcalá de Henares.

Lozano, M. (2006). La maternidad en escena: mujeres, reproducción y representación cultural. Zaragoza: Prensas Universitarias y Ayuntamiento de Zaragoza. 
Maza, Elena (1987): Pobreza y asistencia social en España. Siglos XVI al XX. Valladolid: Universidad de Valladolid.

Nash, M. (1994a). Experiencia y aprendizaje: la formación histórica de los feminismos en España. Historia Social, 20, 151-172.

Nash, M. (1994b). Ordenamiento jurídico y realidad social del aborto en España. Una aproximación histórica. En Ordenamiento jurídico y realidad social de las mujeres, siglo XVI al XX (pp. 223-238). Madrid: Universidad Autónoma.

Ortiz, N. (2003). Trabajo, salarios y movimientos sociales de las mujeres en la Restauración. En J. Cuesta (dir.), Historia de las mujeres en España. Siglo XX (pp. 257-322). Madrid: Instituto de la Mujer.

Palacio, I. (2007). Mujeres aleccionando a mujeres. Discursos sobre la maternidad en el siglo XIX. Historia de la educación, 26, 111-142. Recuperado de http://revistas.usal.es/index.php/02120267/article/view/742

Palomares, J. M. (1988). La condición obrera en la España de la Restauración. En De la beneficencia al bienestar social: cuatro siglos de acción social (pp. 71-97). Madrid: Siglo XXI.

Perinat, A. y Marrades, M. I. (1980). Mujer, prensa y sociedad en España. Madrid: Centro de Investigaciones Sociológicas.

Prats, LL. (1996). La Catalunya rància. Barcelona: Altafulla.

Ríos, R. E. (2006). Sueños de moralidad. La construcción de la honestidad femenina. En I. Morant (dir.), Historia de las mujeres en España y América Latina. Vol. III (pp. 181-206). Madrid: Cátedra.

Ríos, R.E. (2010). Mater amantissima. La representación de la madre en la literatura y la pintura española (1875-1914). En G. Franco (ed.), Debates sobre la maternidad desde una perspectiva histórica (siglos XVI-XX) (pp. 105125). Barcelona: Icaria. 
Rodríguez, A. M. (2003). El castigo del deseo femenino en la Casa de Maternidad y Expósitos de Barcelona, 1853-1903. En M. J. de la Pascua et al. (ed.), Mujer y deseo (pp. 511-517). Cádiz: Universidad de Cádiz.

Rodríguez, A. M. (2005). Las mujeres y la beneficencia en la segunda mitad del siglo XIX. La Casa Provincial de Maternidad y Expósitos de Barcelona, 1853-1903. Tesis doctoral inédita, Universidad de Barcelona.

Rodríguez, A. M. (2008). El destino de los niños de la Inclusa de Pontevedra, 1872-1903. Cuadernos de Estudios Gallegos, 121, 353-388.

Rodríguez, A. M. (2009). Una estrategia de supervivencia familiar en Barcelona, en la segunda mitad del siglo XIX. En P. Gonzalbo (coord.), Familias y relaciones diferenciales: género y edad (pp. 167-183). Murcia: Universidad de Murcia.

Rodríguez, A. M. (2010). Las Casas de Maternidad en España en la segunda mitad del siglo XIX. El caso de Zaragoza. En G. Franco (ed.), Debates sobre la maternidad desde una perspectiva histórica (siglos XVI-XX) (pp. 165-187). Barcelona: Icaria.

Roigé, X. (1977). Família burgesa, família obrera. Evolució dels models de parentiu i industrialització a Barcelona, s. XIX-1930. En J. Roca (coord.), L'articulació social de la Barcelona contemporània (pp. 159-179). Barcelona: Institut Municipal d'Història de Barcelona y Edicions Proa.

Serrano, E. (1980). Alimentos adulterados y defunciones. Apuntes para el estudio de la vida obrera en España. Estudios de Historia Social, 15, 297-303.

Sotelo, A. (2005). Leopoldo Alas y Doña Berta. En V. Trueba et al. (eds.), Lectora, heroína, autora (La mujer en la literatura del siglo XIX) (pp. 347-355). Barcelona: Universidad de Barcelona. 
Tatjer, M. (2002). Demografia de la immigració i el seu assentament a Barcelona als segles XIX i XX. En C. Fauria y Y. Aixelà (coord.), Barcelona, mosaïc de cultures (133-156). Barcelona: Edicions Bellaterra.

Uribe, A. (1996). Marginalidad protegida: mujeres y niños abandonados en Navarra 18901930. Bilbao: Universidad del País Vasco.

Valverde, L. (1994). Entre el deshonor y la miseria. Infancia abandonada en Guipúzcoa y Navarra. Siglos XVIII y XIX. Bilbao: Universidad del País Vasco. 